\title{
An exploration of trends in and predictors of students' perception of health policy education at a Jesuit medical school
}

\author{
Lauren Ditrio', Peggy Weissinger ${ }^{2}$, Michael Plankey $^{2}$ \\ ${ }^{1}$ School of Medicine, Georgetown University School of Medicine, ${ }^{2}$ Medicine, Georgetown University Medical Center \\ Keywords: medical education, medical students, affordable care act, underserved populations, health policy \\ https://doi.org/10.52504/001c.3418
}

Georgetown Medical Review

Vol. 2, Issue 1, 2018

\begin{abstract}
Background: Studies have shown an increase in percent of students reporting "adequate" health policy education in medical schools over the past decade. This study identifies which student characteristics — such as race/ethnicity, intended specialty, and plans to work with underserved populations - are associated with reporting "appropriate" vs "inadequate" health policy education at a Jesuit medical institution in the US.

Methods: Responses from the AAMC Graduation Questionnaire (GQ) for years 2010-2013 to an outcome question evaluating time spent on health policy curriculum were extracted. A multivariable logistic regression analysis was performed to test which student sociodemographic and clinical career training choices impacted satisfaction of health policy education.

Results: The percent of respondents reporting inadequate time spent on health policy curricula decreased significantly between 2010 and 2013. Students who identified their race/ethnicity as Under-Represented in Medicine were significantly less likely to report appropriate health policy education $(\mathrm{OR}=$ $0.419, \mathrm{CI}=0.191-0.919, \mathrm{p}=0.03)$. Other characteristics including male gender, enrollment in a combined degree program, intention to work as university faculty, and intention to serve in an underserved area were also negatively associated with reporting appropriate education; however, these differences were not statistically significant. Furthermore, students in 2013 were significantly more likely to report adequate education compared with those in 2010 (OR $=1.973$, CI 1.001-3.891, $\mathrm{p}=0.0497$ ).

Conclusions: While an increasing majority of students report appropriate exposure to health policy education, medical students who are planning to work with underserved populations may still benefit from additional elective education on health policy.
\end{abstract}

In recent years, public discourse has increasingly focused on health policy and reform. With the passage of the Patient Protection and Affordable Care Act (ACA), which included provisions for Medicaid expansion, coupled with a growing elderly population in the US, federal policy will have a great future impact on the practice of medicine.

In published editorials, medical students ${ }^{1-6}$ as well as professors and administrators ${ }^{2,3}$ recognize the importance that health care policies will play in the careers of future physicians. Independent of a career in health policy research, a solid foundation in health policy basics is essential in medical education. Survey-based research also supports the view that students feel health policy education is important but lacking in current curricula. According to a 2005 survey ${ }^{4}$ of first and fourth year medical students randomly selected from among AMA members, $96 \%$ of respondents felt that knowledge of health policy would be important to their career, but less than half reported satisfaction with their school's health policy curriculum. 
In contrast, a 2009 study $^{5}$ used data from the American Association of Medical Colleges (AAMC) Graduation Questionnaire (GQ) to show that student satisfaction with several measures of health policy education increased over a period of four years. It is clear that students' evaluation of the adequacy of their health policy curricula is in a state of flux even as a strong majority recognize health policy as a critical area of their education.

This study examined student evaluation of health policy curriculum at a Jesuit medical school in an urban setting from the years 2010 to 2013 using AAMC GQ data. The association of student sociodemographics and choice of career training plans were investigated, as well as overall trend over time. We were interested in this particular association due to student opinion pieces regarding the importance of health policy in their future careers ${ }^{1,2}$ as well as published surveys which showed a varying amount of support for the ACA among students depending on their intended specialty 6,7 .

\section{Methods}

\section{Population and Sampling Method}

This study used primary data from the AAMC Graduate Questionnaire (GQ) from the years 2010 to 2013 . The GQ has been administered to graduating medical students since 1978. Students graduating from medical school in each year were invited to voluntarily participate in the survey. The survey comprised a number of questions on a wide range of topics, including career plans and evaluation of medical school curriculum ${ }^{6}$. Demographic information was linked to survey responses by the AAMC. The data set was restricted to responses from students at a single large, Jesuit medical school in an urban setting.

\section{Data Collection}

The outcome question was as follows for all survey years: "Do you believe that your instruction in [Population Based Medicine: Health policy] was inadequate, appropriate, or excessive? Respondents could also choose not to respond to the question.

The AAMC provided de-identified data to the researchers including aggregation of race/ethnicity self-identification into two discrete categories: Under-Represented in Medicine (URiM), and All Other.

\section{Data Analysis}

The dataset originally consisted of 704 individuals. Of these, 229 were excluded due to missing values for the outcome variable. For purposes of analysis, responses to the outcome question were dichotomized to "Inadequate" and "Appropriate ". Subjects responding "Excessive" were excluded from the analysis due to low number ( 7 total). As such, the final dataset consisted of 468 
individuals. Missing values for "intention to practice in an underserved area" and "intention to care primarily for an underserved population" were imputed using iterative imputation.

A Chi-square test examined variation in socio-demographics between respondents who answered the outcome question and respondents who did not answer the outcome question. A multivariable logistic regression was performed using these outcomes and the variables listed in Table 2. Odds ratios and confidence intervals for predictors including sociodemographic information and reported career plans are also included in Table 2. Reference categories were as follows: "Female" for sex, "any other" for race, "MD program" for degree program, "Non-academic clinical practice" for intended career, "2010" for year, "no" for intention to serve in an underserved area, and "yes" for intention to care primarily for an underserved population.

\section{Results}

Number of responses each year ranged from 105 (in 2010) to 133 (in 2011). Demographic composition of the final dataset was as follows: $50 \%(234 / 468)$ male vs. 50\% (234/468) female, and $8.55 \%$ (40/468) Under-represented in Medicine vs. 91.45\% (428/468) all other race/ethnicities. Overall, 75.3\% (344/ 468 ) of respondents felt their health policy education was "appropriate", while 26.5\% (124/468) felt it was "inadequate".

A Chi-square analysis was performed between those subjects who answered the outcome question compared with those who did not answer the outcome question. There was no statistically significant difference between the two groups for the following demographic characteristics: sex, race, degree program, intended career (university faculty vs. non-academic clinical practice vs. undecided vs. other) and intention to serve an underserved population. Non-respondents to the outcome question were significantly more likely than respondents to report going into General Surgery, OB/GYN, or Urology compared with respondents $(p<0.001)$. Non-respondents to the outcome question were also significantly more likely than respondents to report no plans to practice in an underserved area or undecided $(\mathrm{p}=0.007)$.

Results for the logistic regression analysis are reported in Table 2. Respondents in 2013 were significantly more likely to report appropriate education on health policy compared with those in 2010 ( $\mathrm{OR}=1.973, \mathrm{p}=0.0497$ ). Compared with all other students, those who self-identified as a race and/ or ethnicity URiM were significantly $(p=0.03)$ less likely to report that their health policy instruction was appropriate with an OR of 0.419 .

Several additional characteristics and career plans were also negatively associated with reporting appropriate education on health policy, though these differences were not statistically significant. Male students were less likely than female students $(\mathrm{OR}=0.906)$ to report appropriate time, as were those in combined degree programs $(\mathrm{OR}=0.702)$, those planning to work as university 


\begin{tabular}{|c|c|c|c|}
\hline Variables & & Counts & Percent \\
\hline \multirow[t]{2}{*}{ Sex } & $\mathrm{F}$ & 234 & $50 \%$ \\
\hline & M & 234 & $50 \%$ \\
\hline \multirow[t]{2}{*}{ Race } & Any Other & 428 & $91.45 \%$ \\
\hline & URiM & 40 & $8.55 \%$ \\
\hline \multirow[t]{2}{*}{ Degree Program } & MD Program & 462 & $98.72 \%$ \\
\hline & $\mathrm{MD} / \mathrm{PhD}$ or $\mathrm{MD} / \mathrm{MBA}$ & 6 & $1.28 \%$ \\
\hline \multirow[t]{4}{*}{ Intended Career } & Non-Academic Clinical Practice & 123 & $28.08 \%$ \\
\hline & University Faculty & 235 & $53.65 \%$ \\
\hline & Undecided & 52 & $11.87 \%$ \\
\hline & Other & 28 & $6.39 \%$ \\
\hline \multirow[t]{4}{*}{ Intended Specialty } & $\mathrm{IM}$ & 81 & $17.31 \%$ \\
\hline & Other & 249 & $53.21 \%$ \\
\hline & Peds/FM & 42 & $8.97 \%$ \\
\hline & Surg/OBGYN/Urology & 96 & 20.51 \\
\hline \multirow[t]{4}{*}{ Graduation Year } & 2010 & 105 & $22.44 \%$ \\
\hline & 2011 & 133 & $28.42 \%$ \\
\hline & 2012 & 108 & $23.08 \%$ \\
\hline & 2013 & 122 & $26.07 \%$ \\
\hline \multirow[t]{3}{*}{ Intention to practice in an underserved area } & No & 157 & $33.55 \%$ \\
\hline & Yes & 109 & $23.29 \%$ \\
\hline & Undecided & 202 & $43.16 \%$ \\
\hline \multirow[t]{3}{*}{ Intention to care primarily for an underserved population } & Yes & 89 & $19.02 \%$ \\
\hline & No & 206 & $44.02 \%$ \\
\hline & Undecided & 173 & $36.97 \%$ \\
\hline \multirow[t]{2}{*}{ Health Policy Education } & Inadequate & 124 & $26.5 \%$ \\
\hline & Appropriate & 344 & $73.5 \%$ \\
\hline
\end{tabular}

faculty $(\mathrm{OR}=0.87)$, and those planning to work in underserved areas $(0.886)$. Students who reported a specialty preference for Pediatrics or Family Medicine were less likely to report their training was appropriate $(\mathrm{OR}=0.888)$ compared with the referent, which was Internal Medicine. However, those who preferred Surgery, OB/GYN, or Urology were more likely to report appropriate training than those planning on practicing Internal Medicine $(\mathrm{OR}=1.062)$.

\section{Discussion}

The Liaison Committee on Medical Education (LCME) standards define areas in which medical schools must provide "content of sufficient breadth and depth to prepare medical students for entry into any residency program and for the subsequent contemporary practice of medicine" ${ }^{8}$. Underlying this requirement is the concept that there is a minimum amount of training which all students must receive in order to prepare for their future careers, regardless of any planned specialization or restriction of the scope of their practice. While we do not disagree, it is important to note that subsets of students may feel they require a greater amount of training than the minimum standard for accreditation. Graduate medical education may address some of the differences 
Table 2: Descriptive Statistics by Graduation Year

\begin{tabular}{|c|c|c|c|c|c|c|}
\hline Variables & & 2010 & 2011 & 2012 & 2013 & Total \\
\hline$n(\%)$ & & $\begin{array}{l}105 \\
(22.4 \%)\end{array}$ & $\begin{array}{l}133 \\
(28.4 \%)\end{array}$ & $\begin{array}{l}108 \\
(23.1 \%)\end{array}$ & $\begin{array}{l}122 \\
(26.1 \%)\end{array}$ & $\begin{array}{l}468 \\
(100 \%)\end{array}$ \\
\hline \multirow[t]{3}{*}{$\begin{array}{l}\text { Intention to practice in an underserved } \\
\text { area }\end{array}$} & Yes & $\begin{array}{l}27 \\
(25.7 \%)\end{array}$ & $\begin{array}{l}29 \\
(21.8 \%)\end{array}$ & $\begin{array}{l}28 \\
(25.9 \%)\end{array}$ & $\begin{array}{l}25 \\
(20.5 \%)\end{array}$ & $\begin{array}{l}109 \\
(23.3 \%)\end{array}$ \\
\hline & No & $\begin{array}{l}41 \\
(39.1 \%)\end{array}$ & $\begin{array}{l}42 \\
(31.6 \%)\end{array}$ & $\begin{array}{l}37 \\
(34.3 \%)\end{array}$ & $\begin{array}{l}37 \\
(30.33 \%)\end{array}$ & $\begin{array}{l}157 \\
(33.6 \%)\end{array}$ \\
\hline & Undecided & $\begin{array}{l}37 \\
(35.2 \%)\end{array}$ & $\begin{array}{l}62 \\
(46.6 \%)\end{array}$ & $\begin{array}{l}43 \\
(39.8 \%)\end{array}$ & $\begin{array}{l}60 \\
(49.2 \%)\end{array}$ & $\begin{array}{l}202 \\
(43.2 \%)\end{array}$ \\
\hline \multirow[t]{3}{*}{$\begin{array}{l}\text { Intention to care primarily for an } \\
\text { underserved population }\end{array}$} & Yes & $\begin{array}{l}20 \\
(19.1 \%)\end{array}$ & $\begin{array}{l}23 \\
(17.3 \%)\end{array}$ & $\begin{array}{l}31 \\
(28.7 \%)\end{array}$ & $\begin{array}{l}15 \\
(12.3 \%)\end{array}$ & $\begin{array}{l}89 \\
(19.0 \%)\end{array}$ \\
\hline & No & $\begin{array}{l}52 \\
(49.5 \%)\end{array}$ & $\begin{array}{l}53 \\
(39.9 \%)\end{array}$ & $\begin{array}{l}44 \\
(40.7 \%)\end{array}$ & $\begin{array}{l}57 \\
(46.7 \%)\end{array}$ & $\begin{array}{l}206 \\
(44.0 \%)\end{array}$ \\
\hline & Undecided & $\begin{array}{l}33 \\
(31.4 \%)\end{array}$ & $\begin{array}{l}57 \\
(42.9 \%)\end{array}$ & $\begin{array}{l}33 \\
(30.6 \%)\end{array}$ & $\begin{array}{l}50 \\
(41.0 \%)\end{array}$ & $\begin{array}{l}173 \\
(37.0 \%)\end{array}$ \\
\hline \multirow[t]{2}{*}{ Health Policy Education } & Inadequate & $\begin{array}{l}31 \\
(29.5 \%)\end{array}$ & $\begin{array}{l}39 \\
(29.3 \%)\end{array}$ & $\begin{array}{l}34 \\
(31.5 \%)\end{array}$ & $\begin{array}{l}20 \\
(16.4 \%)\end{array}$ & $\begin{array}{l}124 \\
(26.5 \%)\end{array}$ \\
\hline & Adequate & $\begin{array}{l}74 \\
(70.5 \%)\end{array}$ & $\begin{array}{l}94 \\
\text { (70.7\%) }\end{array}$ & $\begin{array}{l}74 \\
(68.5 \%)\end{array}$ & $\begin{array}{l}102 \\
(83.6 \%)\end{array}$ & $\begin{array}{l}344 \\
(73.5 \%)\end{array}$ \\
\hline
\end{tabular}

Table 3: Logistic Regression Model Results

\begin{tabular}{|c|c|c|c|c|c|c|}
\hline & Reference & Variable & OR & $\begin{array}{l}\text { Lower } \\
\mathrm{CL}\end{array}$ & $\begin{array}{l}\text { Upper } \\
\mathrm{CL}\end{array}$ & $\begin{array}{l}\mathrm{p}- \\
\text { values }\end{array}$ \\
\hline & & Intercept & 3.49 & 1.23 & 9.93 & 0.01 \\
\hline Sex & Female & Male & 0.90 & 0.57 & 1.43 & 0.67 \\
\hline Race/Ethnicity & All other & URiM & 0.41 & 0.19 & 0.91 & 0.03 \\
\hline Degree Program & MD & $\mathrm{MD} / \mathrm{PhD}$ or $\mathrm{MD} / \mathrm{MBA}$ & 0.70 & 0.11 & 4.20 & 0.69 \\
\hline \multirow[t]{2}{*}{ Career Type } & $\begin{array}{l}\text { Community } \\
\text { Practice }\end{array}$ & University Faculty & 0.87 & 0.51 & 1.45 & 0.59 \\
\hline & & Undecided & 1.45 & 0.63 & 3.24 & 0.38 \\
\hline \multirow[t]{3}{*}{ Specialty } & IM & Other & 0.84 & 0.45 & 1.56 & 0.59 \\
\hline & & Pediatrics/FM & 0.88 & 0.35 & 2.21 & 0.79 \\
\hline & & $\begin{array}{l}\text { Surgery/OBGYN/ } \\
\text { Urology }\end{array}$ & 1.06 & 0.51 & 2.17 & 0.86 \\
\hline \multirow[t]{2}{*}{ Underserved Area } & No & Yes & 0.88 & 0.41 & 1.88 & 0.75 \\
\hline & & Undecided & 0.63 & 0.33 & 1.19 & 0.16 \\
\hline \multirow[t]{2}{*}{$\begin{array}{l}\text { Underserved } \\
\text { Population }\end{array}$} & Yes & No & 1.04 & 0.50 & 2.13 & 0.91 \\
\hline & & Undecided & 1.04 & 0.50 & 2.13 & 0.91 \\
\hline \multirow[t]{3}{*}{ Year } & 2010 & 2011 & 0.81 & 0.44 & 1.47 & 0.49 \\
\hline & & 2012 & 0.88 & 0.47 & 1.64 & 0.70 \\
\hline & & 2013 & 1.97 & 1.00 & 3.89 & 0.04 \\
\hline
\end{tabular}

in perceived need for training among students; however, as this study demonstrates, subsets of undergraduate medical students already feel that they require more targeted instruction. 
We hypothesized that the amount of HPE each student felt was adequate would vary in association with their planned career settings, and that student satisfaction with a standard curriculum would vary similarly. As a Jesuit institution, our medical school comprises many faculty, staff, and students who have a special interest in social justice. Hence, the question of whether future physicians felt they were receiving an adequate education in health policy was of particular interest to us. With increased research on factors associated with student satisfaction with their education, it may be possible to develop curricula to better address the needs of specific subsets of students.

Previous studies have examined trends in student perception of their HPE, but not whether these perceptions are associated with sociodemographics or career plans. Patel et al. ${ }^{9}$ showed that a higher percentage of students in 2011-2012 reported receiving appropriate amounts of education on a number of topics relating to health policy compared with students in 2007-2008. Demographics and career plans did not change over time, and thus they postulated that changes in the student population did not account for the change in satisfaction.

In contrast, our study examined the association of demographics and intended careers with students' perception of their HPE. While this study showed an effect of career preference on perception of HPE as adequate, the reason for this effect is unclear. Because this study focused on a single institution, it may be posited that differences in student evaluation of the appropriateness of their education are related to different perceptions of the amount needed, not differences in the amount received. It is possible that students planning to work in underserved areas and/or with underserved populations were less likely to report appropriate education due to an increased perceived need for HPE compared with their peers. In regards to students planning careers in Family Medicine (FM) or Pediatrics being more likely to report inadequate education, it may be posited that this is due to an increased interest in health policy among those fields. FM/Pediatrics, compared with surgical fields, traditionally have a particular interest in health policy, and their professional organizations including the American Academy of Family Physicians (AAFP) ${ }^{10}$ and the American Academy of Pediatrics (AAP) ${ }^{11}$ often advise on health policy and preventive care guidelines.

Students who identified as URiM were significantly less likely to report adequate time spend on HPE. Again due to the single-institution focus of this study, it is likely that this represents a different level of interest or perceived need for HPE among these students, rather than a difference in the amount of time spent. URiM physicians are more likely to work in primary care than are other physicians ${ }^{12,13}$, which may account for the increased interest in health policy among our URiM students. Furthermore, we would postulate that 
URiM students have a greater awareness of systemic inequality and social determinants of health, and thus perceive a greater need for learning about health policy in medical school.

Of interest, we found a significantly increased percentage of students reporting adequate instruction in 2013 compared with 2010. This agrees with studies showing a national shift toward improving percentages of students reporting adequate instruction ${ }^{9}$. However, in contrast to these national studies, which do not track curriculum changes at each institution, our analysis examined this shift in the context of a single curriculum. Because no new courses on health policy were introduced at the institution in the years of follow-up, the improved percentage of students reporting appropriate instruction cannot be said to be due to formal curriculum changes. It is possible that these improved percentages may be a reflection of informal small group discussion with course preceptors, or of increased student participation in existing classes and therefore improved perception of learning during the years immediately following the passage of the Affordable Care Act.

In conclusion, this study shows that a subset of students planning careers in underserved areas or with underserved populations have a perceived need for health policy education which is not being met by the current curriculum. It would be advantageous to offer an elective, which would supplement the existing health policy curriculum for those students with a special interest.

\section{Authors' Contributions}

LD - study design, manuscript authorship. PW - study design, manuscript revision. MP - study design, manuscript revision.

\section{Acknowledgments}

This material is based on data provided by the Association of American Medical Colleges (AAMC). The views expressed herein are those of the authors and do not necessarily reflect the position or policy of the AAMC. The authors have used these data with permission in accordance with the releasing and licensing policy. The authors wish to acknowledge the contribution of Anagha Patel, MS to the statistical analysis performed in this paper.

\section{Conflict of interest and funding}

This project was funded by the [redacted]. There was no conflict of interest.

\section{Ethical approval}

This study was approved by the [redacted] Institutional Review Board, [redacted], United States. 


\section{REFERENCES}

1. Cullen E. Health policy in medical education: what young physicians know about the Affordable Care Act. Archives of Internal Medicine. 2012;172(20):1605.

2. Mou D, Sarma A, Sethi R, Merryman R. The state of health policy education in U.S medical schools. N EnglJ Med. 2011;364(10):e19.

3. Riegelman R. Commentary: Health systems and health policy: a curriculum for all medical students. Academic Medicine. 2006;81(4):391.

4. Agrawal JR, Hedgecock J, Sehgal AR, Jung P, Simon SR. Medical students' knowledge of the U.S. health care system and their preferences for curricular change: a national survey. Academic Medicine. 2005;80(5):484.

5. Patel MS, Lypson ML, Davis MM. Medical student perceptions of education in health care systems. Academic Medicine. 2009;84:1301.

6. Huntoon KM, McCluney CJ, Scannell CA, Wiley EA, Bruno R, Andrews A, et al. Healthcare reform and the next generation: United States medical student attitudes toward the Patient Protection and Affordable Care Act. PLoS ONE. 2011;6(9):e23557.

7. Winkelman TN, Lehmann LS, Vidwan NK, Niess M, Davey CS, Donovan D, et al. Medical Students' Views and Knowledge of the Affordable Care Act: A Survey of Eight U.S Medical Schools. J Gen Intern Med. 2015;30(7):1018-1024.

8. LCME. Functions and Structure of a Medical School: Standards for Accreditation of Medical Education Programs Leading to the MD Degree. 2016.

9. Patel MS, Lypson ML, Miller DD, Davis MM. A framework for evaluating student perceptions of health policy training in medical school. Academic Medicine. 2014;89(10):1375.

10. American Association of Family Physicians. Vision and Strategic Plan. http://www.aafp.org/ about/the-aafp/vision.html. Accessed April 26, 2016.

11. American Academy of Pediatrics. AAP Facts: Policy and Clinical Guidance. https://www.aap.org/en-us/about-the-aap/aap-facts/Pages/AAP-Facts.aspx. Accessed April 26, 2016.

12. Xu G, Fields SK, Laine C, Veloski JJ, Barzansky B, Martini CJ. The relationship between the race/ethnicity of generalist physicians and their care for underserved populations. Am J Public Health. 1997;87(5):817-822.

13. Xu G, Veloski J, Hojat M, Politzer RM, Rabinowitz HK, Rattner SL. Factors influencing primary care physicians' choice to practice in medically underserved areas. Acad Med. 1997;72(10 Suppl 1):S109-11. 